ORIGINAL ARTICLE

\title{
Positive association of the DIO2 (deiodinase type 2) gene with mental retardation in the iodine-deficient areas of China
}

\author{
T-W Guo*, F-C Zhang*, M-S Yang, X-C Gao, L Bian, S-W Duan, Z-J Zheng, J-J Gao, H Wang, \\ R-L Li, G-Y Feng, D St Clair, L He
}

J Med Genet 2004;41:585-590. doi: 10.1136/img.2004.019190

See end of article for authors' affiliations

.....................

Correspondence to:

L He, Bio-X Life Science Research Center, PO Box 501, Hao Ran Building, Shanghai Jiao Tong University, 1954 Hua Shan Road, Shanghai 200030, China; helin@sjtu.edu.cn

Revised version received 18 March 2004

Accepted for publication 24 March 2004
Background: lodine deficiency is the commonest cause of preventable mental retardation (MR) worldwide. However, in iodine-deficient areas not everyone is affected and familial aggregation is common. This suggests that genetic factors may also contribute. Thyroid hormone (TH) plays an important role in fetal and early postnatal brain development. The pro-hormone T4 (3,3',5,5'-triiodothyronine) is converted in the brain to its active form, T3, or its inactive metabolite, reverse T3, mainly by the action of deiodinase type 2 (DIO2).

Methods: To investigate the potential genetic contribution of the DIO2 gene, we performed a case-control association study using three common SNPs in the gene (rs225014, rs225012, and rs225010) that were in strong linkage disequilibrium with each other.

Results: Single marker analysis showed a positive association of MR with rs225012 and rs225010. Particularly with rs225012, TT genotype frequency was significantly higher in MR cases than in controls $\left(\chi^{2}=9.18, p=0.00246\right)$. When we compared the distributions of common haplotypes, we also found significant differences between mental retardation and controls in the haplotype combination of rs225012 and rs225010 ( $\chi^{2}=15.04$, df 2 , global $\left.p=0.000549\right)$. This association remained significant after Bonferroni correction $(p=0.0016470)$.

Conclusion: We conclude that allelic variation in the DIO2 gene may affect the amount of T3 available and in an iodine-deficient environment may partly determine overall risk of MR.
$\mathrm{F}$ tal iodine deficiency is the commonest cause of preventable mental retardation. ${ }^{1}$ Every year, 100000 children are born with frank cretinism, and many times more are born with lesser mental and neurological deficits attributable to iodine deficiency, ${ }^{2}$ as a result of inadequate amounts of thyroid hormone (TH) being available to the developing fetal brain. Thyroid hormones regulate the processes of terminal brain differentiation such as dendritic and axonal growth, synaptogenesis, neuronal migration and myelination. TH also modulates the establishment of neuronal networks through regulation of the number of microglial cells producing neurotrophic factors. ${ }^{3}$

The deiodinase play a key role in the maintenance of circulating and tissue levels of thyroid hormones. There are three types of deiodinase, type 1, 2, and 3 (DIO1, DIO2, and DIO3) iodothyronine. All are seleno-enzymes characterised by a selenocysteine in the catalytic domain of the enzyme encoded by a UGA codon in the presence of a characteristic 3' untranslated region stem loop structure, the selenocysteine insertion sequence (SECIS). DIO2 is particularly important in the brain. The pro-hormone T4 $\left(3,3^{\prime}, 5,5^{\prime}\right.$-triiodothyronine) is converted in the brain to its active form, T3, or its inactive metabolite, reverse T3, mainly by the action of DIO2. DIO2 is involved in an activation step converting 3,5,3' $5^{\prime}$-tetraiodothyronine (T4) to 3,5,3'-tri-iodothyronine (T3), and a degradation step converting $3,3^{\prime} 5^{\prime}$-triiodothyronine (reverse T3) to 3,3'-diiodothyronine. Inactivation steps are mainly regulated by deiodinase type 3 (DIO3) when converting T4 to reverse $\mathrm{T} 3$ and converting $\mathrm{T} 3$ to $3,3^{\prime}$-diiodothyronine. ${ }^{4}$ DIO2 appears to be a tissue-specific regulator of intracellular $\mathrm{T} 3$ concentrations in the brown fat, brain, and pituitary. ${ }^{5}$ The DIO2 gene maps to human chromosome $14 \mathrm{q} 24.3$, is about
$15 \mathrm{~kb}$ in size, and the coding region is divided into two exons by a gap of approximately $7.4 \mathrm{~kb} .{ }^{6}$ In light of the important action of thyroid hormone in brain development and the regulation of the active form of thyroid hormone by DIO2 in the brain, and as, up to now, there have few genetic studies performed in this specific field, we decided to evaluate whether allelic variation in the DIO2 gene might alter risk of susceptibility for MR in areas of iodine deficiency.

\section{METHODS \\ Sample}

The study included three groups, definite mental retardation (MR; $\mathrm{n}=96)$, borderline mental retardation (border; $\mathrm{n}=116)$, and controls $(\mathrm{n}=331)$. The mean (SD) age of groups was 9.9 (2.9) years with a 49:51 female-male ratio (table 1). All subjects were identified and recruited from Zha Shui and An Kang counties in the Qin-Ba mountain region of Shaanxi province, Western China. There is widespread soil erosion in this region (average elevation 750-1500 m) and water iodine levels are low; we recorded an iodine (SD) level in water of $1.87(0.46) \mu \mathrm{g} / \mathrm{l}^{7}$ There is no selenium deficiency. For several years the Shaanxi province health authorities have conducted iodination programs and popularised the use of iodine enriched common salt. This has resulted in a marked decline in the frequency of mental retardation in the Qin-Ba mountain region. However, the prevalence of mental retardation $(2.78 \%)$ still remains higher than in most other areas of China (1.07\%). ${ }^{8}$ Moreover, we found familial clustering in the two counties with several families displaying

Abbreviations: $L D$, linkage disequilibrium; $M R$, mental retardation; $\mathrm{PCR}$, polymerase chain reaction; $\mathrm{TH}$, thyroid hormone 
Table 1 Number of samples collected in each area, sex ratio and mean age

\begin{tabular}{|c|c|c|c|c|c|c|c|c|c|c|c|c|}
\hline Area & MR & $\begin{array}{l}\text { Sex ratio } \\
\text { (F/M) }\end{array}$ & $\begin{array}{l}\text { Mean age } \\
\text { (SD) }\end{array}$ & Border & $\begin{array}{l}\text { Sex ratio } \\
\text { (F/M) }\end{array}$ & $\begin{array}{l}\text { Mean age } \\
\text { (SD) }\end{array}$ & Controls & $\begin{array}{l}\text { Sex ratio } \\
\text { (F/M) }\end{array}$ & $\begin{array}{l}\text { Mean age } \\
\text { (SD) }\end{array}$ & Total & $\begin{array}{l}\text { Sex ratio } \\
\text { (F/M) }\end{array}$ & $\begin{array}{l}\text { Mean age } \\
\text { (SD) }\end{array}$ \\
\hline Zha Shui & 52 & $26 / 26$ & $10.9(2.8)$ & 74 & $40 / 30$ & $10(3.0)$ & 245 & $118 / 124$ & $9.6(2.8)$ & 371 & $184 / 184$ & $9.9(2.9)$ \\
\hline An Kang & 44 & $24 / 20$ & $9.6(2.8)$ & 42 & $20 / 22$ & $10.9(3.1)$ & 86 & $39 / 47$ & $9.7(3.0)$ & 172 & $82 / 89$ & $9.9(3.0)$ \\
\hline Total & 96 & $50 / 46$ & $10.3(2.8)$ & 116 & $60 / 56$ & $10.4(3.1)$ & 331 & $156 / 171$ & $9.6(2.9)$ & 543 & $266 / 273$ & $9.9(2.9)$ \\
\hline
\end{tabular}

multiple affected members in one or more generations. It is possible that genetic factors may interact with an iodinedeficient physical environment to determine overall risk of mental retardation.

\section{Ethics}

All subjects gave standard informed consent after explanation of the study. The protocol was reviewed and approved by the Ethical Committee of the National Human Genome Center. All subjects were Han Chinese in origin.

\section{Screening for social adaptability or mental handicap} Participants were screened using the Adaptive Scale of Infant and Children revised by Zuo et al. ${ }^{9}$ Using these scales each person was given a social adaptive score or mental handicap score. Those with no disability on these scales invariably have an IQ within normal range and, for purposes of the study, were therefore classified as normal controls.

\section{IQ testing}

Children 4-5 years old were tested with the ChineseWechsler Young Children Scale of Intelligence (C-WYCSI), ${ }^{10}$ while those 6-16 years old were tested with the ChineseWechsler Intelligence Scale for Children (C-WISC). ${ }^{11}$ We selected an IQ of less than 70 as the cut-off for mental retardation (MR). We defined IQs of less than 70 accompanied by social disability scores of 8 or less as mental retardation (MR), and IQs of 70-79 with social disability scores of 9 as borderline MR (border).

\section{Neurological examination}

It was usually not possible or appropriate to perform a formal IQ test in cases of frank cretinism, and we had to depend upon clinical diagnosis. A neurological examination, conducted by a physician, included tests of hearing, vision, voice and speech, reflexes, and posture and gait. We excluded from the study cases of MR if affected by trachoma, infection, trauma, toxicity, cerebral palsy, or birth complications. Controls came from the same iodine-deficient areas and were selected from families with no history of MR. If permission was granted, a blood sample was taken for routine haematology, serology, and DNA analysis. Blood samples were stored at $-20^{\circ} \mathrm{C}$. Genomic DNA was extracted from blood using a modified phenol/chloroform method.

\section{Power analysis}

We performed power calculations based on Cohen's method ${ }^{12}$ using $G^{*}$ Power software and Epi info 2002. The present sample size showed over $90 \%$ power to detect significance $(\alpha<0.05)$ in the association with allele, genotype, and haplotype under study conditions and an effect size index of 0.2 corresponding to "weak to moderate" gene effect was used. Furthermore, the present sample sizes had a power of $>73 \%$ at $p=0.05$ to detect allelic association of the allele, genotype, and haplotype at a presumed odds ratio (OR) of 2 .

\section{SNPs in the DIO2 region}

We selected SNPs located in the DIO2 region from information sourced from the SNP Consortium (http://snp.cshl.org/) and dbSNP (http://www.ncbi.nlm.nih.gov/SNP/) and examined their allele frequencies in 24 controls ( 48 chromosomes) by the direct sequencing procedure described below. After evaluation of 22 SNPs by seven pairs of sequencing primer, we selected three SNPs with minor allele frequencies of over 0.05 in the DIO2 gene. They were $r s 225014(\mathrm{~A} / \mathrm{G})$ in exon 2, and $r s 225012(\mathrm{~T} / \mathrm{C})$ and $r s 225010(\mathrm{~A} / \mathrm{G})$ in intron 1. rs 225014 and rs225012 have an interval of $1.2 \mathrm{kbp}$ and rs225012 and rs 225010 have an interval of $1.5 \mathrm{kbp}$.

The SNP rs225014 (A/G) in exon 2 was amplified by polymerase chain reaction (PCR) using the primers: forward: 5'-TACCTGCCATCATGCCTCTT-3', and reverse: 5'-GGAAGT CAGCCACTGAGGAG -3'. PCRs were carried out in 96-well microtitre plates with a final reaction volume of $25 \mu \mathrm{l}$ containing $50 \mathrm{mM} \mathrm{KCl}, 10 \mathrm{mM}$ Tris- $\mathrm{HCl}(\mathrm{pH} \mathrm{8.0)}, 1.5 \mathrm{mM}$ $\mathrm{MgCl}_{2}, 200 \mathrm{mM}$ dNTPs, $5 \mu \mathrm{l}$ Q solution (Qiagen, Valencia, CA, USA), $10 \mathrm{pM}$ each primer, $20 \mathrm{ng}$ DNA, and $2.5 \mathrm{U}$ Taq polymerase (Life Technologies, Karlsuhe, Germany). Cycle conditions were one cycle with an initial 4 min denaturation at $95^{\circ} \mathrm{C}$, followed by 35 cycles of $94^{\circ} \mathrm{C}$ for $30 \mathrm{~s}, 57^{\circ} \mathrm{C}$ for $40 \mathrm{~s}$, $72^{\circ} \mathrm{C}$ for $50 \mathrm{~s}$, and a final extension period at $72^{\circ} \mathrm{C}$ for $10 \mathrm{~min}$, using the GeneAmp PCR System 9700 (Applied BioSystems, Foster City, CA). SNPs were typed by direct sequencing. The PCR products were processed by incubation with $0.1 \mathrm{U}$ of shrimp alkaline phosphatase (Roche, Basel, Switzerland) and $0.5 \mathrm{U}$ of exonuclease I (New England Biolabs, Beverly, MA) at $37^{\circ} \mathrm{C}$ for $1 \mathrm{~h}$, followed by heat inactivation at $80^{\circ} \mathrm{C}$ for $20 \mathrm{~min}$. The PCR products were sequenced with reverse PCR primer as the sequencing primer using an ABI Prism BigDye Terminator Cycle Sequencing Kit (Applied BioSystems, Foster City, CA) on an ABI Prism 377 or 3100 sequencer.

The genotyping of SNPs $r s 225012$ (T/C) and $r s 225010$ (A/G) combines kinetic (real-time quantitative) PCR with allelespecific amplification, which has been described elsewhere. ${ }^{13}$ We used two separate real-time quantitative PCR reactions, each of which contains an allele-specific primer of SNP and the same common primer. Heterozygous samples have equal amounts of the two alleles, which should reach a detectable level of fluorescence at the same cycle number, but in heterogeneity the cycle number should be different for the two amplification reactions. For the $r s 225012$ (T/C) polymorphism a $55 \mathrm{bp}$ PCR product was amplified using the common primer: 5'-GTGCAAAGGGAGCACATGAA-3', a T allele-specific primer: 5'-TAAAATATTGGGGCAGAAGAA-3', and a $\mathrm{C}$ allele-specific primer: 5'-TAAAATATTGGGG CAGAAGAG-3'. Amplification was performed in a $5 \mu \mathrm{l}$ volume of $2.5 \mu \mathrm{l} 2 \times$ TaqMan universal PCR master mix (Applied Biosystems), $10 \mathrm{ng}$ genomic DNA, $0.2 \mu \mathrm{M}$ allelespecific primer, $0.2 \mu \mathrm{M}$ common primer, and $0.2 \times \mathrm{SYBR}$ Green I (Molecular Probe). The PCR cycles began with an UNG digestion stage at $50^{\circ} \mathrm{C}$ for $2 \mathrm{~min}$, and an initial denaturation period at $95^{\circ} \mathrm{C}$ lasting for $10 \mathrm{~min}$, followed by 50 cycles at $95^{\circ} \mathrm{C}$ for $15 \mathrm{~s}$, an annealing phase conducted at $59^{\circ} \mathrm{C}$ for $30 \mathrm{~s}$, and a dissociation stage at $95^{\circ} \mathrm{C}$ for $15 \mathrm{~s}$. For the rs225010 (A/G) polymorphism a $55 \mathrm{bp}$ PCR product was amplified under the same cycling conditions except with the following primers: the common primer: 5'-AAATTTAT CTGCCTCAGTGAGCTT-3', an allele-specific primer: 5' GAACATAATCATATTTGGGTGAT-3', and a G allele-specific 
Table 2 Genotypes and allele frequencies for the three SNPs

\begin{tabular}{|c|c|c|c|c|c|c|c|c|c|c|c|c|}
\hline \multirow{3}{*}{$\begin{array}{l}\text { Polymorphism } \\
\text { rs225014 }\end{array}$} & & & \multicolumn{6}{|l|}{$\chi^{2}$ (p value) } & \multicolumn{2}{|c|}{$\chi^{2}$ (p value) } & \multirow{2}{*}{\multicolumn{2}{|c|}{$\begin{array}{l}\text { Odds ratio } \\
(95 \% \mathrm{Cl})\end{array}$}} \\
\hline & \multicolumn{2}{|c|}{$\begin{array}{l}\text { Genotype } \\
\text { frequency }\end{array}$} & \multirow{2}{*}{$\begin{array}{l}\text { MR versus } \\
\text { control }\end{array}$} & \multirow{2}{*}{$\begin{array}{l}\text { Border versus } \\
\text { control }\end{array}$} & \multirow[t]{2}{*}{ Total } & \multirow[t]{2}{*}{$\begin{array}{l}\text { Success rate } \\
\text { of genotyping }\end{array}$} & \multicolumn{2}{|c|}{$\begin{array}{l}\text { Allele frequency } \\
(\%)\end{array}$} & \multirow[t]{2}{*}{ MR } & \multirow[t]{2}{*}{ Border } & & \\
\hline & AA & GA GG & & & & & A & G & & & & \\
\hline$M R$ & 12 & $43 \quad 39$ & 0.72 & 0.86 & 94 & 97.9 & 0.6467 & 0.3533 & 0.45 & 0.09 & 1.123 & 1.049 \\
\hline Border & 23 & $44 \quad 47$ & (0.39) & (0.35) & 114 & 98.3 & 0.6053 & 0.3947 & 0.5 & 0.76046 & $\begin{array}{l}(0.801 \text { to } \\
1.573)\end{array}$ & $\begin{array}{l}(0.771 \text { to } \\
1.428)\end{array}$ \\
\hline Controls & 54 & 145131 & & & 330 & 99.7 & 0.6159 & 0.3841 & & & & \\
\hline$r s 225012$ & $\mathrm{TT}$ & TC CC & $\begin{array}{l}T \text { and } \\
\text { TC versus CC }\end{array}$ & $\begin{array}{l}\Pi T \text { versus TC } \\
\text { and } C C\end{array}$ & & & $\mathrm{~T}$ & C & & & & \\
\hline MR & 52 & $30 \quad 12$ & 9.18 & 0.45 & 94 & 97.9 & 0.2935 & 0.7065 & 4.59 & & 1.491 & 1.111 \\
\hline Border & 75 & $35 \quad 5$ & $(0.00246)$ & (0.5) & 115 & 99.1 & 0.1957 & 0.8043 & $(0.03)$ & $(0.58225)$ & $\begin{array}{l}\text { (1.033 to } \\
2.152 \text { ) }\end{array}$ & $\begin{array}{l}(0.763 \text { to } \\
1.617)\end{array}$ \\
\hline Controls & 203 & 11214 & & & 329 & 99.4 & 0.2119 & 0.7881 & & & & \\
\hline rs225010 & AA & $A G G G$ & $\begin{array}{l}\text { AA versus } \\
\text { GG }\end{array}$ & $\begin{array}{l}\text { AA versus } \\
\text { GG }\end{array}$ & & & A & G & & & & \\
\hline$M R$ & 11 & $40 \quad 42$ & 4.05 & 0.11 & 93 & 96.9 & 0.663 & 0.337 & 4.01 & 1.13 & 1.43 & 1.214 \\
\hline Border & 7 & 3770 & $(0.044)$ & $(0.74)$ & 114 & 98.3 & 0.7763 & 0.2237 & $(0.045)$ & (0.28712) & $\begin{array}{l}\text { (1.006 to } \\
2.031)\end{array}$ & $\begin{array}{l}\text { (0.849 to } \\
1.734)\end{array}$ \\
\hline Controls & 21 & 129180 & & & 330 & 99.7 & 0.7242 & 0.2576 & & & & \\
\hline
\end{tabular}

Bold font indicates significantly associated statistic.

primer: 5'-GAACATAATCATATTTGGGTGAC-3'. To check for genotyping errors, eight DNA samples were randomly selected from each 96-well plate and re-genotyped. All genotypes were identical to those obtained from the first round of genotyping.

\section{Statistical analysis}

Allele frequencies were calculated using the SPSS 10.0 software for Windows (SPSS, Chicago, IL). Deviations from Hardy-Weinberg equilibrium, differences in allele and genotype distributions, and OR with $95 \%$ confidence intervals were calculated using the method of Finetti. ${ }^{14}$ Linkage disequilibrium (LD) between two loci was measured using a two-locus LD calculator (2LD) $)^{15}$ and EMLD software (http:// request.mdacc.tmc.edu/ qhuang/Software/pub.htm). Haplotypes were inferred by Bayesian methods, ${ }^{16}$ and implemented in the PHASE package version 1.0 (http://www.assertion.net/ software/). Differences in genotype and haplotype distribution between patient and control groups were assessed by the Monte Carlo method using the CLUMP program version 1.9 with 10000 simulations. ${ }^{17}$ Statistical significance was set at $\mathrm{p}<0.05$. Odds ratios with $95 \%$ confidence intervals were estimated for the effects of high-risk haplotype and calculated by Epi info 2002 software (http://www.cdc.gov/ epiinfo/). Power analysis was performed using the $\mathrm{G}^{*}$ Power program $^{18}$ and Epi info 2002 software.

\section{RESULTS}

\section{SNPs}

The $r s 225014 \mathrm{SNP}$ is an $\mathrm{A} / \mathrm{G}$ polymorphism in exon 2 of the DIO2 gene, predicting a change in amino acid 92 of the protein (Thr92Ala). The minor allele G frequency of rs225014 was 0.3841 in the control population with a distribution meeting Hardy-Weinberg equilibrium $(p=0.201)$. The rs225012 and rs225010 SNPs are in intron 1 of the DIO2 gene. rs225012 is a T/C SNP with a minor allele T frequency of 0.2935 in our control population and an allele frequency of 0.272 in the Caucasian population. $r$ s225010 is an A/G SNP with a minor allele $G$ frequency of 0.337 in our control population. The distributions of genotypes of rs 225012 and rs225010 were both in Hardy-Weinberg equilibrium in controls. All samples were grouped together for statistical analysis because no significant difference was found in distribution of genotype frequencies between sample from Zha Shui and An Kang counties $(\mathrm{p}>0.35)$.

\section{Singular-locus association analysis}

Table 2 shows the group genotypes and allele frequencies of the three SNPs. No significant difference was observed in genotypes or allele frequencies for the three SNPs between borderline mental retardation and control groups. When MR and controls were compared, rs225014 also revealed no significant difference in allele frequency $(p=0.5)$ or distribution of genotypes $(p=0.39)$. The $G$ allele frequency of rs225010 was higher in MR (0.337) than in controls $(0.2576$; $\mathrm{p}=0.045 ; \mathrm{OR}=1.43,95 \%$ confidence interval 1.006 to 2.031 ). The T allele frequency of $r s 225012$ was higher in MR (0.2935) than in controls $(0.2119 ; \mathrm{p}=0.03$; OR $=1.491$, $95 \%$ confidence interval 1.033 to 2.152). The CC genotype frequency was significantly higher in MR (0.128) than in controls (0.043; $\chi^{2}=9.18, \mathrm{p}=0.00246 ; \mathrm{OR}=3.29,95 \%$ confidence interval 1.37 to 7.91 ).

\section{Haplotype analysis}

To calculate the extent of LD in pairwise combinations of the three SNPs, we calculated $\mathrm{D}^{\prime}, \mathrm{r}^{2}$, and the $\mathrm{p}$ value, the

Table 3 Pairwise linkage disequilibrium

\begin{tabular}{|c|c|c|c|c|c|c|c|c|}
\hline & \multicolumn{4}{|c|}{ rs225012 } & \multicolumn{4}{|l|}{ rs225010 } \\
\hline & D & $\mathbf{D}^{\prime}$ & $r^{2}$ & $p$ & D & $\mathbf{D}^{\prime}$ & $r^{2}$ & $p$ \\
\hline rs225014 & 0.0712 & $\begin{array}{l}0.8741 \\
\text { (SD 0.0465) }\end{array}$ & 0.1282 & $<0.0001$ & -0.0731 & $\begin{array}{l}0.7381 \\
\text { (SD 0.0575) }\end{array}$ & 0.118 & $<0.0001$ \\
\hline rs225012 & & & & & -0.1359 & $\begin{array}{l}0.8642 \\
\text { (SD 0.0335) }\end{array}$ & 0.57864 & $<0.0001$ \\
\hline
\end{tabular}


Table 4 Haplotype frequencies between controls and MR

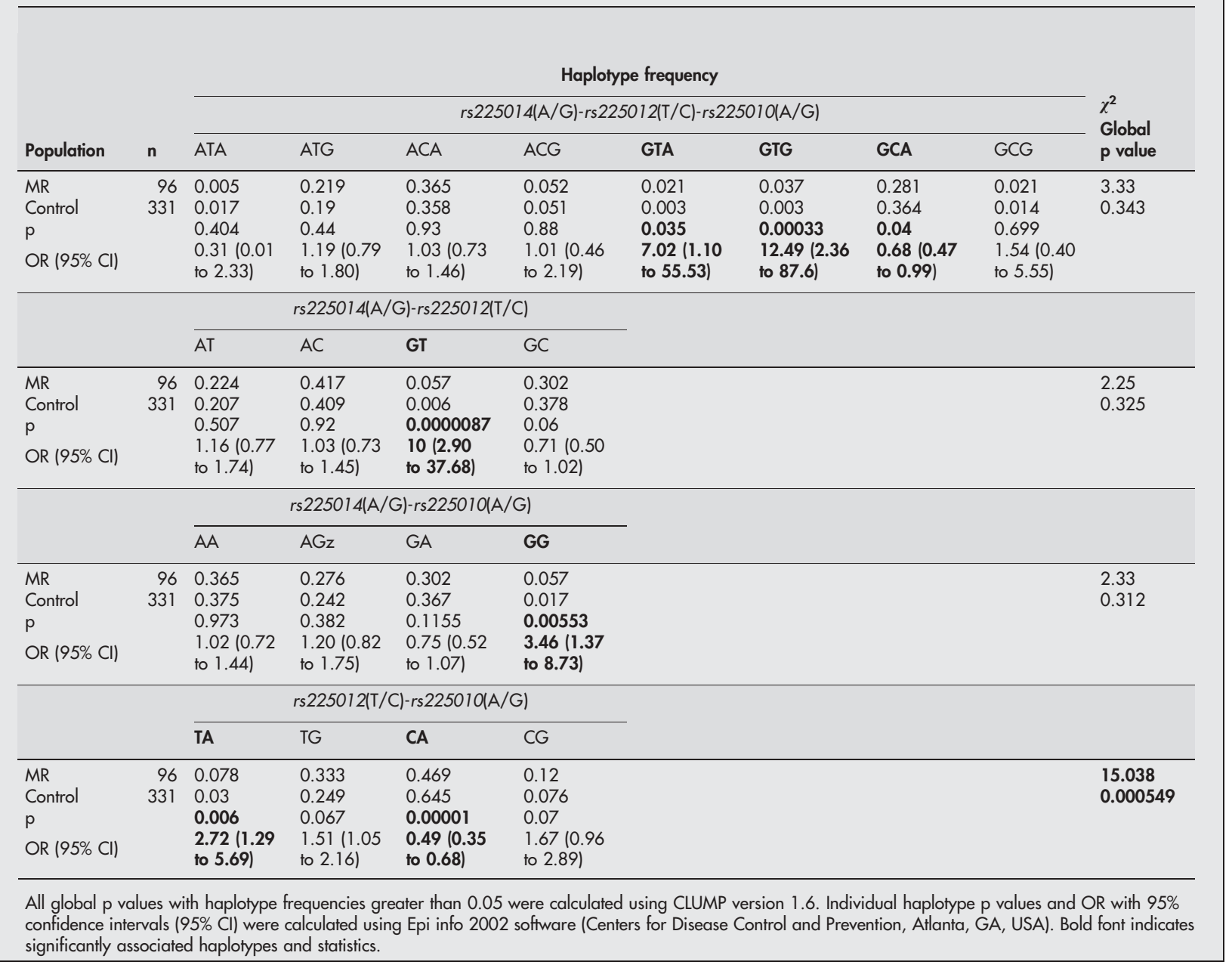

normalised linkage disequilibrium statistic, in controls for all possible pairs of SNPs. The pairwise LD values are shown in table 3. Strong linkage disequilibrium among the three SNPs was observed (all $\mathrm{D}^{\prime}>0.7, \mathrm{p}<0.00001$ ).

We constructed four sets of haplotypes. Three were derived from various combinations of two SNPs and one was derived from a combination of all three SNPs. All the haplotypes were estimated with the PHASE package (table 4).

We only found significant differences between controls and mental retardation in the haplotype of combination of rs225012 and rs225010 $\left(\chi^{2}=15.04\right.$, df 2, global $\left.\mathrm{p}=0.000549\right)$. Furthermore, the data obtained from the study of haplotypes containing either rs225012C or rs225010A showed that the frequency of haplotype C-A was much lower in MR than in controls $\left(\chi^{2}=19.36\right.$, df $1, p=0.00001 ; \quad$ OR $=0.49, \quad 95 \%$ confidence interval 0.35 to 0.68 ). The three marker haplotypes GTA, GTG, GCA are all risk haplotypes for mental retardation, but haplotype GTG has the highest odds ratio $(\mathrm{OR}=12.49,95 \%$ confidence interval: 2.36 to 87.6$)$.

\section{DISCUSSION}

In this study, we investigated the relationship between three polymorphisms in the $\mathrm{DIO} 2$ gene and mental retardation in a Chinese Han population from the Qin-Ba mountain region, a traditionally iodine-deficient area in northwest China. This study has several strengths. First, we showed that our sample size had reasonable power to detect association even when these variants had small to medium effects ( effect size $=0.2$ ) on susceptibility. Furthermore, our child samples may be less influenced by non genetic social and culture factors than adult samples. Second, all subjects came from the Qin-Ba mountain region, a relatively isolated area in northwest China. Moreover, we did not find a significant difference in allele frequencies between the two counties, which reduced the risk of stratification bias. Third, according to the definition of mental retardation, ${ }^{19}$ significantly subaverage intellectual functioning with an IQ score of 70-75 or below on a standardised individual intelligence test is classified as MR. In order to ensure the diagnosis of mental retardation, we set 70 as the IQ cut-off point of MR and classified the individuals identified with IQs of 70-79 as having borderline mental retardation. Finally we have obtained a significant result even after Bonferroni correction. $r s 225014(\mathrm{~A} / \mathrm{G})$ is a coding polymorphism (Thr92Ala) predicting a change in amino acid 92 of the protein. rs225012 (C/T) and rs225010 $(\mathrm{A} / \mathrm{G})$ are located in intron 1 .

Single-locus analysis showed a positive association of MR with markers rs225012 and rs225010. When we compared the distributions of common haplotypes between control and MR, we also found significant differences between controls and mental retardation in the haplotype with combined rs225012 and rs225010. This association was still significant $(\mathrm{p}<0.001647)$ after Bonferroni correction. ${ }^{20}$ The haplotypes of rs225012C and rs225010A showed that C-A was much more frequent in controls than in MR $\left(\chi^{2}=19.36, \mathrm{df} 1, \mathrm{p}=0.00001\right)$ and suggests a protective effect. We analysed whether or not two SNPs were located near an mRNA splicing site through in silico analysis by GENESPLICER (developed by 
the Institute for Genomic Research (TIGR), http://www.tigr.org/ $\mathrm{tdb} /$ GeneSplicer/gene_spl.html ${ }^{21}$ and found they were not.

Another possibility is that $r s 225012$ and rs225010 and the haplotype combination with these two SNPs may simply be in linkage disequilibrium with a functional polymorphism elsewhere in the DIO2 gene or in a gene nearby. The nearest functional polymorphism in the DIO2 gene is $r s 225014(\mathrm{~A} / \mathrm{G})$, a common non conservative variant which predicts a Thr92Ala substitution. Although the crystal structure of type 2 deiodinase is not yet known, it is worth noting that this non conservative amino acid change (aliphatic for polar group), which is not located within the conserved deiodinase catalytic domain, could potentially affect its activity. ${ }^{22}$ However, this region of the enzyme is not phylogenetically conserved. The homologous amino acid is represented by a proline in rodents and by a glycine in chick. In contrast, humans and amphibians share a threonine in this position. It is reported that this SNP is associated with obesity and insulin resistance. ${ }^{23}$ However, we found no association between this polymorphism and mental retardation.

The nearest functional candidate genes are PSENI (presenilin l) and TSHR (thyroid hormone receptor or thyrotropin receptor). PSENI is reported to be associated with early-onset Alzheimer disease type 3. ${ }^{24}$ TSHR is a important gene involved both in the metabolic pathway of thyroid hormones and in a wide range of sporadic and hereditary or genetically determined changes in thyroid function such as thyroid adenomas, thyroid cancer, non autoimmune hyperthyroidism, thyrotropin resistance, and congenital hypothyroidism. ${ }^{25}$ Therefore, the effect of the combination of DIO2, PSEN1, and TSHR may play an important role in the pathogenesis of mental retardation.

It is also possible that the protective haplotype is in linkage disequilibrium with a regulatory element that affects expression of type 2 deiodinase. This in turn may influence T3 levels in the fetal brain and, if the brain is already compromised by iodine deficiency, influence the risk of mental retardation. Eighty per cent of brain T3 is formed through the enzymatic activity of type 2 deiodinase (DIO2). DIO2 is mainly found in astrocytes in vitro and vivo, ${ }^{26}$ suggesting that circulating T4 is metabolised into $\mathrm{T} 3$ in the glial cells and then transferred to the neurons. To examine the physiological role of DIO2, Schneider et $a^{27}$ developed a DIO2 knockout mouse strain lacking DIO2 activity. Mice homozygous for the targeted deletion had no gross phenotypic abnormalities, and development and reproductive function appeared normal, except for mild growth retardation in males. It is unclear whether a similar situation pertains for DIO2 deficiency in human fetal brain whose thyroid hormone function is already compromised by iodine deficiency. We suspect that normal deiodinase type 2 may be an important protection factor from late in the first trimester and early in the second trimester of gestation, because in this period DIO2 activity in the brain is evidently increased..$^{28}$ Further work is required to investigate the mechanisms by which DIO2 may affect fetal brain development in the context of iodine deficiency.

\section{ACKNOWLEDGEMENTS}

We sincerely thank all participants in this study.

\section{ELECTRONIC-DATABASE INFORMATION}

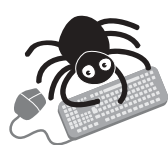

URL for data in this article are as follows: Locuslink: http://www.ncbi.nlm.nih.gov/LocusLink/ (for SNP selection); dbSNP: http://www.ncbi.nlm.nih.gov/ SNP/ (for SNP selection); the SNP Consortium: http:// snp.cshl.org/ (for SNP selection); GeneSplicer: http://www.tigr.org/tdb/GeneSplicer/gene_spl.html (for splicer site analysis of mRNA).

\section{Authors' affiliations}

T-W Guo, M-S Yang, L Bian, S-W Duan, J-J Gao, H Wang, L He, Institute for Nutritional Science, Chinese Academy of Sciences, 320 Yue Yang Road, Shanghai 200031, China

T-W Guo, M-S Yang, L Bian, S-W Duan, J-J Gao, L He, Bio-X Life Science Research Center, Shanghai Jiao Tong University, Shanghai 200030, China

F-C Zhang, X-C Gao, Z-J Zheng, Institute of Population and Health, Northwest University, Xi'an 710069, China

R-L Li, The Second Hospital, Xi'an Jiao Tong University, Xi'an 710049, China

G-Y Feng, Shanghai Institute of Mental Health, 600 South Wan Ping Road, Shanghai 200030, China

D St Clair, Department of Mental Health, University of Aberdeen, Medical School, Foresterhill, Aberdeen, AB25 2ZD, UK

This work was supported by grants from the national 973 and 863 programs, the National Natural Science Foundation of China, and the Shanghai Municipal Commission for Science and Technology.

Conflict of interest: none declared.

*The first two authors contributed equally to this work.

\section{REFERENCES}

1 WHO. National strategies for overcoming micronutrient malnutrition, 89th Session EB 89/27 (unpublished document A45/17). Geneva, Switzerland: WHO, 1992.

2 Wang HY, Zhang FC, Gao JJ, Fan JB, Liu P, Zheng ZJ, Xi H, Sun Y, Gao XC, Huang TZ, Ke ZI, Guo GR, Feng GY, Breen G, Clair DS, He L. Apolipoprotein $\mathrm{E}$ is a genetic risk factor for fetal iodine deficiency disorder in China. Mol Psychiatry 2000;5(4):363-8.

3 Mallat M, Lima FR, Gervais A, Colin C, Moura NV. New insights into the role of thyroid hormone in the CNS: the microglial track. Mol Psychiatry $2002 ; 7(1): 7-8$.

4 Salvatore D, Low SC, Berry M, Maia AL, Harney JW, Croteau W, St Germain DL, Larsen PR. Type 3 iodothyronine deiodinase: cloning, in vitro expression, and functional analysis of the placental selenoenzyme. J Clin Invest 1995;96(5):2421-30.

5 Kohrle J. Local activation and inactivation of thyroid hormones: the deiodinase family. Mol Cell Endocrinol 1999;151(1-2):103-19.

6 Celi FS, Canettieri G, Yarnall DP, Burns DK, Andreoli M, Shuldiner AR, Centanni M. Genomic characterization of the coding region of the human type II 5'-deiodinase gene. Mol Cell Endocrinol 1998;141(1-2):49-52.

7 Zhang Z-F, Wang Z-L, Zhang R-J, Gong F-L, Wang Z. The iodine nutritive status of pregnant women and wet nurses in the Qin-Ba mountain areas. Chin J Endemiol 2001;20(3):201-3

8 Li F, Yan F, Han Z, Yang W, Li X, Li Y. A study of the relationship between health care during labour and children's mental retardation in QinBa mountain area, Shaanxi province. J Xi'an Med Univ 1999;20(1):100-2.

9 Zuo QH, Zhang ZhX, Lei ZhW. Adaptive Scale of Infant and Children. Beijing, China: Medical University of China, 1988.

10 Gong YX, Dai XY. Chinese-Wechsler Young Children Scale of Intelligence (C-WYCSI). Hunan, China: Map Press, 1992.

11 Gong YX, Cai TSh. Wechsler Intelligence Scale for Children, Chinese revision (C-WISC). Hunan, China: Map Press, 1993.

12 Cohen J. Statistical power analysis for the behavioral sciences, 2nd ed. Hillsdale, NJ: Lawrence Erlbaum Associates, 1988:215-71

13 Germer S, Holland MJ, Higuchi R. High-throughput SNP allele-frequency determination in pooled DNA samples by kinetic PCR. Genome Res 2000; 10(2):258-66.

14 Sasieni PD. From genotypes to genes: doubling the sample size. Biometrics 1997;53(4):1253-61.

15 Zhao JH. 2LD two-locus linkage disequilibrium LD calculator, 2002. http:// www.iop.kcl.ac.uk/loP/Departments/PsychMed/GEpiBSt/software.shtml (accessed April 29, 2004).

16 Stephens M, Smith NJ, Donnelly P. A new statistical method for haplotype reconstruction from population data. Am J Hum Genet 2001;68(4):978-89.

17 Sham PC, Curtis D. Monte Carlo tests for associations between disease and alleles at highly polymorphic loci. Ann Hum Genet 1995;59(Pt 1):97-105.

18 Erdfelder E, Faul F, Buchner A. G*Power: a general power analysis program. Behav Res Methods Instrum Comput 1996;28:1-11.

19 American Association on Mental Retardation. Mental retardation: definition, classification and systems of supports-workbook. Washington, DC: American Association on Mental Retardation, 1992.

20 Perneger TV. What's wrong with Bonferroni adjustments. BMJ 1998;316(7139):1236-8.

21 Pertea M, Lin X, Salzberg SL. GeneSplicer: a new computational method for splice site prediction. Nucleic Acids Res 2001;29(5):1185-90.

22 Buettner C, Harney JW, Larsen PR. The role of selenocysteine 133 in catalysis by the human type 2 iodothyronine deiodinase. Endocrinology 2000; 141(12):4606-12.

23 Mentuccia D, Proietti-Pannunzi L, Tanner K, Bacci V, Pollin TI, Poehlman ET, Shuldiner AR, Celi FS. Association between a novel variant of the human type 2 deiodinase gene Thr92Ala and insulin resistance: evidence of interaction with the Trp64Arg variant of the beta-3-adrenergic receptor. Diabetes 2002;51(3):880-3 
24 Sherrington $R$, Rogaev El, Liang $Y$, Rogaeva EA, Levesque $G$, Ikeda $M$, Chi H, Lin C, Li G, Holman K. Cloning of a gene bearing missense mutations in earlyonset familial Alzheimer's disease. Nature 1995;375(6534):754-60.

25 Paschke R, Ludgate $M$. The thyrotropin receptor in thyroid diseases. N Engl J Med 1997;337(23):1675-81.

26 Li WW, Le Goascogne C, Schumacher M, Pierre M, Courtin F. Type 2 deiodinase in the peripheral nervous system: induction in the sciatic nerve after injury. Neuroscience 2001;107(3):507-18
27 Schneider MJ, Fiering SN, Pallud SE, Parlow AF, St Germain DL, Galton VA Targeted disruption of the type 2 selenodeiodinase gene (DIO2) results in a phenotype of pituitary resistance to T4. Mol Endocrinol 2001;15(12):2137-48

28 Croteau W, Davey JC, Galton VA, St Germain DL. Cloning of the mammalian type II iodothyronine deiodinase. A selenoprotein differentially expressed and regulated in human and rat brain and other tissues. J Clin Invest 1996;98(2):405-17.

\section{Making Health Care Safer 2004}

21-22 October 2004

Royal College of Physicians, London

A two day conference for all professionals dedicated to providing safer health care for all.

Register now! Early booking discount available.

See website for details: www.quality.bmipg.com 


\section{PostScript}

\section{BOOK REVIEW}

\section{Hereditary Hearing Loss and its Syndromes, 2nd edn}

Edited by H V Toriello, W Reardon, R J Gorlin. Oxford University Press, 2004, £110, pp 502. ISBN 0-19-513849-X

Although formally classified as the second edition, this is essentially the third version of the groundbreaking book by Bruce Konigsmark and Bob Gorlin entitled Genetic and Metabolic Deafness as originally published in 1976. Subsequent recognition of the pressing need to incorporate the rapid expansion in knowledge of new syndromes prompted the appearance of the first editon of Hereditary Hearing Loss and its Syndromes in 1995, as a sister publication to Syndromes of the Head and Neck. This new edition represents the coming of age of the marriage between molecular biology and conventional clinical genetics and provides an excellent state of the art synthesis of contemporary knowledge.

A reviewer's task in making criticism of an outstanding and definitive textbook is not an easy one. In planning this new edition the editors have resisted the temptation to tinker with a successful format to the extent that the overall structure is virtually unchanged. The existing chapter on endocrine and metabolic disorders has been split into two and the miscellaneous chapter has disappeared, to be replaced by a chapter on cardiac syndromes. Otherwise the chapter headings are as in the previous edition with much of their text reproduced, albeit with expanded sections on "heredity" to embrace the many new discoveries of the last few years. Thus the contents can be subdivided into four introductory chapters which set the scene, followed by 12 chapters describing system associated hearing loss syndromes. In general these are excellent, with each providing detailed accounts of an exhaustive list of common and rare conditions in which hearing loss can occur. All these are lavishly illustrated with ample references for those who wish to delve further.
Against this background of general excellence any possible hint of criticism might well be viewed as petty and inappropriate, so it is hoped that the editors will forgive a few personal comments. Most readers will be very familiar with the basic principles of human genetics so that on turning to the chapter on genetic counselling it was disappointing to find that this is largely limited to an explanation of traditional patterns of inheritance. The real challenge facing most clinical geneticists and genetic counsellors is how to counsel the hearing parents of a child with isolated non-syndromal hearing loss. Chapter 2 provides useful suggestions for investigation but the subsequent chapter on genetic counselling provides little in the way of assistance. True, there is a useful table (of unstated source) providing empirical risks, but with little in the way of guidance as to how these should be applied. Should these risks be modified on the basis of age of onset, laterality, asymmetry, progression, vestibular involvement, audiology or a normal Connexin 26/30 mutation analysis? Presumably they should, but how? The editors and chapter authors embrace most of the world's experts on genetic hearing loss and it is a little unfortunate that they could not expand on this crucial component of the counselling process. An overview of how genes and their products interact to facilitate the hearing process would also be useful, as would expansion of some of the sections on molecular pathogenesis in the system orientated chapters. Finally, the era when medical books can include full frontal nude photographs of children and adults must be coming to a close and one wonders how many of the stark naked adults appearing in some of the syndrome chapters gave informed consent for their publication in perpetuity.

Clearly these are minor criticisms of an excellent textbook which will provide an invaluable resource and be consulted widely. It is difficult to see how any department encountering patients with hearing loss could possibly manage without it.

I Young

\section{CORRECTIONS}

doi: 10.1136/jmg.2005.18333corr 1 An error has been detected in the online mutation report by Burdon et al ( $\mathrm{J}$ Med Genet 2004:41:el06). The mutation is identified in the manuscript as $226 \mathrm{G}>\mathrm{A}$ in regards to the Genbank reference NM_021954. However, it should be $227 \mathrm{G}>\mathrm{A}$. The amino acid designation, $\mathrm{R} 76 \mathrm{H}$, is correct and this numbering error does not change any of the other results or conclusions of the article. The author apologises for this error.

doi: 10.1136/jmg.2004.013151corr 1 Several errors have been detected in the electronic letter by Toyama et al ( $\mathrm{J}$ Med Genet 2004;41:e74).

First, the abbreviations for Table 1 should read:

Ex, exon; (FAM)-,FAM-labelled; (HEX)-, HEX-labelled; (ROX)-,ROX-labelled; (NED)NED-labelled; UP, upstream; Pro, prometer, Int, intron; Fl, flanking; STR, short tandem repeat.

Second, the parenthesised section of the last sentence of the Results should read:

$(7.3 \pm 1.3 \mathrm{mmol} / \mathrm{l}(\mathrm{K} 287 \mathrm{I})$ and $7.63 \pm 1.0$ $\mathrm{mmol} / \mathrm{l}$ (M310I) compared to that of the wild type $(3.8 \pm 0.4 \mathrm{mmol} / \mathrm{l})$.

In addition, in Ex4 of Table 3 the "Type" should read C235 (R79W), in Figure 1 "Euro. $\mathrm{Am}^{\prime \prime}$ is the abbreviation for "European American," and in Table 4 the title should read "Catalytic activity of recombinant AMPDl expressed in E. coli".

We apologise for these errors.

doi: 10.1136/jmg.2004.019190corr 1

The authors for the paper titled Positive association of the DIO2 (deiodianase type 2) gene with mental retardation in the iodinedeficient areas of china $(J$ Med Genet 2004:41;585-590) have identified an error within their abstract. The second line from the results section should read: Particularly with rs255012, CC genotype frequency was significantly higher in MR cases than in controls (chi squared $=9.18, p=0.00246$ ) . The author apologises for this mistake. 